\title{
GROWING APART: FURTHER ANALYSIS OF INCOME TRENDS IN THE 1990S
}

\section{Ann Harding}

National Centre for Social and Economic Modelling University of Canberra

\section{BACKGROUND}

There has been debate in Australia about whether income inequality is increasing. Using annual income data, a range of studies suggested that income inequality increased in the $1980 \mathrm{~s} .{ }^{1,2}$ Using weekly income data, Harding found that income inequality had remained stable between 1982 and 1993-94, ${ }^{3}$ and between 1982 and 1996-97. ${ }^{4}$ However, it has since emerged that there may be major problems with the weekly income data collected in the 1982 Income Survey, so that there are now doubts about the reliability of results based on this data. In addition, recent research conducted by the National Centre for Social and Economic Modelling (NATSEM) has also suggested that income inequality in the 1996-97 Income Survey looks much too equal, relative to earlier and later surveys. ${ }^{5}$ These issues, of possible data problems and data comparability, are currently being examined in a joint project by the Australian Bureau of Statistics (ABS) and the Social Policy Research Centre. This current article is thus restricted to an analysis of data collected at the end of the 1980s and in the 1990s.

\section{INCOME TRENDS}

This article uses weekly income data from two sets of national sample surveys undertaken by the Australian Bureau of Statistics to look at income inequality trends in the 1990s. The methodology of the study is described in detail in Harding and Greenwell. ${ }^{5}$ In summary, the data sources are the unit record tapes released by the ABS for the Household Expenditure Surveys and the Income
Surveys; the income unit used is the household; 'dependent children' means all persons aged less than 18 years living in the household except where the young person lived by themselves, with a spouse, or in a group household; the equivalence scale used is the square root of household size, which is widely used internationally; income is current weekly income; in the later surveys negative business and investment incomes have been reset to zero to maintain comparability with the earlier surveys; the measure of resources is disposable (after-income tax) income, adjusted by the equivalence scale to take into account the needs of households of different size; and the income distribution is determined by a ranking of people by their equivalent household income, so that a household containing five people is counted five times, not once, when calculating inequality.

One widely used measure of the change in aggregate income inequality is the Gini coefficient, which varies between 0 (when income is equally distributed) to 1 (when one household holds all income). In general, a higher Gini coefficient is associated with increasing inequality. As Figure 1 shows, data from both the Household Expenditure Surveys and the Income Surveys both suggest that income inequality increased over the course of the 1990s. Thus, the Gini coefficients derived from the Expenditure Surveys increase by 0.016 between 1988-89 and 1998-99, while those derived from the Income Surveys increase by 0.018 between 1990 and 1997-98.

Another popular way of looking at income inequality is to examine real (that is, inflation adjusted) incomes at different points in the income distribution. Percentile 10, for example, is the equivalent disposable household

FIGURE 1

COMPARISON OF GINI COEFFICIENTS FOR EQUIVALENT DISPOSABLE HOUSEHOLD INCOME FROM THE EXPENDITURE AND INCOME SURVEYS

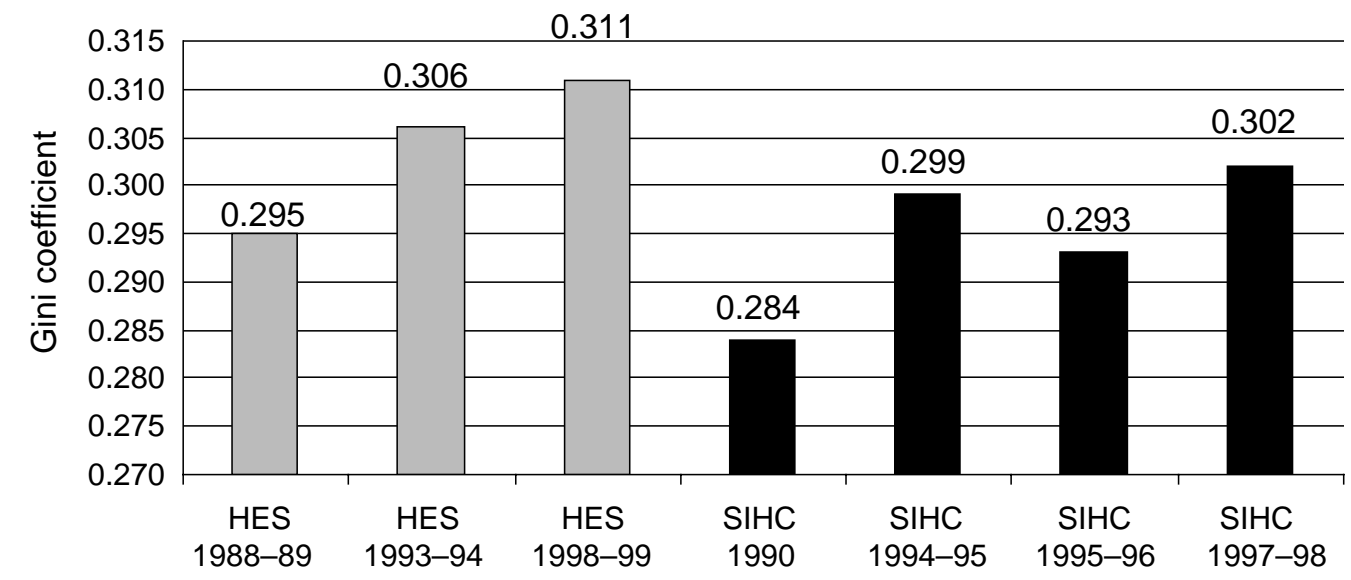

Data source: ABS Household Expenditure Survey and Income Survey unit record files. 
income of the person at the 10th percentile of the income distribution. According to the Household Expenditure Survey, weekly income at this point has remained fairly stable in real terms, rising from A\$393 in 1988-89 to A $\$ 41010$ years later (Table 1). Above this point, incomes at the lower-middle and middle of the income distribution pick up between the 1993-94 and 1998-99 surveys, after little change over the previous five years. But perhaps the most significant movement is at the top end of the distribution, with the average real incomes of those at the 90th and 95th percentiles of the distribution increasing strongly over the last decade - and apparently particularly in the last half of the 1990s. For example, the left hand column in Table 1 indicates that real weekly incomes at the 95th percentile have increased from $A \$ 1770$ to A $\$ 2103$ over the 10 years to $1998-99$, which is an increase of 18.8 per cent.

This suggests that there has been a growing gap between the top and the middle as well as between the top and the bottom. This is confirmed by the ratios between these various income points, shown in the middle panel in Table 1. Both the $90 / 10$ and the $95 / 10$ ratios have increased markedly over the 10 years to 1998-99. The gap between the top and the middle has also grown since 1988-89 but not by as much, as shown by the lesser increase in the 90/
50 ratio over those 10 years. The relative distance between the middle and the bottom has apparently increased in the last 10 years, with median income now reaching 2.17 times that of the 10th percentile.

Do the Income Surveys tell us the same story about income inequality as the Expenditure Surveys? In comparing the two, we have to keep in mind the slightly different time periods covered. In particular, the Expenditure Surveys cover two additional years, so higher increases in income might be expected given the longer time period.

The Income Surveys tell a somewhat different story about what is happening at various points within the income distribution (Table 1). Relative to the Expenditure Surveys, the Income Surveys suggest that:

- the bottom has fared better;

- the middle has fared worse;

- the top has fared less well than indicated in the Expenditure Surveys.

However, there is still some consistency within the results from the two sets of data, in that the top has experienced larger gains in income than either the bottom or the middle over the 1990s. It is also important to note that, even after taking out the impact of inflation, both sets of surveys

\section{TABLE 1}

RANGE OF INDICATORS OF INCOME INEQUALITY, HOUSEHOLD EXPENDITURE SURVEYS AND INCOME SURVEYS

\begin{tabular}{|c|c|c|c|c|c|c|}
\hline & \multicolumn{3}{|c|}{ Expenditure Surveys } & \multicolumn{3}{|c|}{ Income Surveys } \\
\hline & $1988-89$ & 1998-99 & $\begin{array}{r}\% \text { change } \\
1989-99 \\
\end{array}$ & 1990 & 1997-98 & $\begin{array}{c}\% \text { change } \\
90-98 \\
\end{array}$ \\
\hline \multicolumn{7}{|c|}{ Weekly income at particular points in the distribution } \\
\hline 95th percentile & $\$ 1,770$ & $\$ 2,103$ & $18.8 \%$ & $\$ 1,967$ & $\$ 2,121$ & $7.9 \%$ \\
\hline 90th percentile & $\$ 1,533$ & $\$ 1,775$ & $15.8 \%$ & $\$ 1,709$ & $\$ 1,843$ & $7.8 \%$ \\
\hline 75th percentile & $\$ 1,155$ & $\$ 1,318$ & $14.1 \%$ & $\$ 1,326$ & $\$ 1,390$ & $4.9 \%$ \\
\hline Mean & $\$ 908$ & $\$ 1,011$ & $11.4 \%$ & $\$ 1,025$ & $\$ 1,073$ & $4.7 \%$ \\
\hline Median & $\$ 804$ & $\$ 890$ & $10.7 \%$ & $\$ 944$ & $\$ 956$ & $1.3 \%$ \\
\hline 25th percentile & $\$ 542$ & $\$ 586$ & $8.1 \%$ & $\$ 624$ & $\$ 625$ & $0.1 \%$ \\
\hline 10th percentile & $\$ 393$ & $\$ 410$ & $4.2 \%$ & $\$ 443$ & $\$ 449$ & $1.5 \%$ \\
\hline $5^{\text {th }}$ percentile & $\$ 343$ & $\$ 327$ & $-4.6 \%$ & $\$ 364$ & $\$ 376$ & $3.2 \%$ \\
\hline \multicolumn{7}{|l|}{ Ratios } \\
\hline $95 / 10$ ratio (very top/bottom) & 4.5 & 5.13 & $14.1 \%$ & 4.44 & 4.72 & $6.3 \%$ \\
\hline $90 / 10$ ratio (top/bottom) & 3.9 & 4.33 & $11.2 \%$ & 3.86 & 4.1 & $6.3 \%$ \\
\hline $90 / 50$ ratio (top/middle) & 1.91 & 2 & $4.6 \%$ & 1.81 & 1.93 & $6.4 \%$ \\
\hline 50/10 ratio (middle/bottom) & 2.04 & 2.17 & $6.2 \%$ & 2.13 & 2.13 & $-0.1 \%$ \\
\hline \multicolumn{7}{|l|}{ Decile shares } \\
\hline Bottom $10 \%$ & 3.2 & 2.7 & $-14.7 \%$ & 3.1 & 3 & $-3.1 \%$ \\
\hline Bottom $20 \%$ & 8.1 & 7.4 & $-6.3 \%$ & 8 & 7.7 & $-3.7 \%$ \\
\hline Middle $20 \%$ & 17.8 & 17.6 & $-1.2 \%$ & 18.3 & 17.8 & $-2.7 \%$ \\
\hline Top $20 \%$ & 37.4 & 38.2 & $2.1 \%$ & 36.1 & 37.5 & $3.9 \%$ \\
\hline Top $10 \%$ & 22.2 & 22.5 & $1.3 \%$ & 20.9 & 22 & $5.6 \%$ \\
\hline \multicolumn{7}{|c|}{$\begin{array}{l}\text { Note: The income measure is the International equivalent weekly disposable household income of individuals. All incomes have } \\
\text { been adjusted for inflation to March } 2001 \text { dollars, using the CPI. The } 95 / 10 \text { ratio is the ratio between the incomes of those } \\
\text { at the } 95^{\text {th }} \text { percentile of the income distribution with those at the } 10^{\text {th }} \text { percentile of the income distribution. }\end{array}$} \\
\hline \multicolumn{7}{|c|}{ Source: ABS Household Expenditure Survey unit record files. } \\
\hline
\end{tabular}


suggest that both the average and median (middle) households enjoyed higher incomes at the end of the 1990s than at the beginning.

\section{INCOME SHARES}

Finally, the bottom panel of results in Table 1 present a third set of measures commonly used to look at income inequality. This is the share of total income received by various groups in the population. For example, according to the Expenditure Surveys, the poorest 10 per cent of the population saw their share of the income pie decline from 3.2 per cent to 2.7 per cent of the total. Similarly, the middle 20 per cent of the population, when ranked by their household income, experienced a marginal fall in their income share, down to 17.6 per cent of the total pie in 1998-99. The Income Surveys also suggest that the middle and the bottom lost ground over the 1990s. Both surveys indicate that the most affluent 10 and 20 per cent of the population increased their share of the pie.

\section{CONCLUSION}

The results from the two sets of ABS data differ in some respects, but some clear conclusions emerge. First, income inequality has increased over the course of the 1990 s, although it is not entirely clear how much of that increase occurred primarily in the first half of the decade. However, all of the inequality measures used suggest growing income inequality for the decade as a whole.

There has been strong growth in incomes at the top end of the income spectrum. Growth in incomes has been slower at the middle and the bottom of the income spectrum. As a result, the gap between the top and the middle, and between the top and the bottom, has increased during the 1990s. There has been a decline in the share of the total income cake going to the bottom 10 per cent and the middle 20 per cent of Australians. This has been offset by the increase in the share of total income going to the top 20 per cent of Australians.

It is not entirely clear how middle Australia has been faring relative to those on the lowest incomes. The Income Surveys suggest that the middle and the bottom have experienced comparable income increases over the course of the 1990s, so that the relative gap between the incomes of the two groups has remained constant. The Expenditure Surveys paint a very different picture and suggest that middle incomes have increased more rapidly than the incomes of those at the bottom of the income spectrum.

\section{REFERENCES}

1. Saunders P. Economic Adjustment and Distributional Change: Income Inequality in Australia in the EightiesDiscussion Paper No 47. Sydney: Social Policy Research Centre, University of NSW, 1993.

2. Harding A. What is Happening to Income Inequality in Australia? Dialogues on Australia's Future. Peter Sheehan (editor). Melbourne: Centre for Strategic Economic Studies, Victoria University, 1996.

3. Harding A. The Suffering Middle: Trends in Income Inequality in Australia 1982 to 1993-94. Australian Economic Review December 1997; 30(4): 341-58.

4. Harding A. Income Inequality Trends in the 1980s and 1990s. NSW Public Health Bulletin May 2001; 12(5): 134-136.

5. Harding A and Greenwell H. Trends in Income and Expenditure Inequality in the 1980s and 1990s. Paper presented to the 30th Annual Conference of Economists, Perth, Western Australia, 24 September 2001. Available from the NATSEM Web site at www.natsem.canberra.edu.au. 